\title{
Variable displacement axial piston pump: acoustic and functional characterization
}

\author{
GIUSEPPE MICCOLI \\ Earth-Moving Machinery and Off-Road Vehicles Institute \\ CEMOTER - National Research Council \\ via Canalbianco, 28 - 44044 Cassana (Ferrara) - Italy
}

\begin{abstract}
A test method based on the use of a simple circuit made by pump-line-load valve has been applied in order to characterize a variable displacement axial piston pump as to its hydraulic noise. The best anechoic conditions achieved, pump fluidborne noise and internal flow losses are provided by source impedance and ideal flow ripple evaluation. The influence of constructive parameters as pump port plate geometry and swash plate fastener has been taken into account and various working conditions on acoustic and functional performance examined. The limits of the test method identified, an alternative procedure has been proposed making use of simpler experimental data acquisition and computer programs on purpose worked out.
\end{abstract}

\section{KEYWORDS}

Anechoic circuit, flow ripple, impedance, fluidborne noise, pump.

\section{NOMENCLATURE}

$A=$ pipe cross-sectional area, $\mathrm{m}^{2}$

$c=$ fluid sonic velocity, $\mathrm{m} / \mathrm{sec}$

$H=$ pressure ratio

$j=(-1)^{1 / 2}$

$l=$ pipe lenght, $\mathrm{m}$

$P=$ pump pressure ripple, bar

$Q=$ pump flow ripple, $1 / \mathrm{sec}$

$R=$ pipe pressure loss, bar

$Z=$ impedance, $\mathrm{Nsec} / \mathrm{m}^{5}$

$\varrho=$ fluid density, $\mathrm{kg} / \mathrm{m}^{3}$

$\omega=$ pumping frequency, $\mathrm{Hz}$

\section{$\underline{\text { Subscript }}$}

$e=$ entry to delivery line

$l=$ leakage

$$
\begin{aligned}
& o=\text { pipe } \\
& s=\text { source } \\
& 0=\text { pump delivery port position } \\
& 1,01 \text { and } o l=\text { pipe } n .1 \\
& 2,02 \text { and } o 2=\text { pipe } n .2 \\
& 12=1 \text { to } 2 \text { pressure ratio }
\end{aligned}
$$

\section{INTRODUCTION}

Designing pumps with low fluidborne noise potential requires knowledge of two complex quantities, i. e. pump source flow and characteristic source impedance. Their interaction generates pressure ripples responsible of major transient loadings of component casing and connected pipelines so coming out principal causes of noise emission.

The theoretic and experimental procedures here 
described give a precise measurement of these two quantities.

A comparison is shown between the results of two test methods, their application referring to the study of the acoustic and functional performance of a variable displacement axial piston pump.

\section{THEORETICAL BACKGROUND}

The classic plane wave transmission equation can be considered the starting point from which the whole test procedure comes.

Referring to a simple hydraulic circuit made by pump-line-load valve, this equation describes the stationary complex wave in the circuit and the pressure ripple $\mathrm{P}$ at each point. This equation can be written as the resultant of two parts $[1,2]$. The first represents the pump outgoing pressure ripple and shows the wave dependence on the line and source impedance. The second deals with pressure wave propagation.

This equation accounts for the complex standing wave relevant to the flow ripple generated by the pump and propagated down the pipe-line at the speed of sound in the fluid. The flow ripple consists of a complex waveform with major components at frequencies corresponding to the harmonics of the pumping frequency. Its interaction with the source impedance and the hydraulic circuit and its multiple reflections at hydraulic components as valve and pump itself are all taken into account so that the pressure ripple $\mathrm{P}$ at any point is dependent on both pump and circuit characteristics.

In order to evaluate the source impedance $Z_{s}$ and the pump ideal flow ripple $\mathrm{Q}_{s}$, the equation above can be simplified getting rid of the influence of the pressure ripple of the circuit downstream the pump. That is the same as having the pump connected to a reflectionless line and measuring the pressure ripple just at the pump delivery port.

This way being both the termination reflection coefficient and the distance of the first pressure transducer from the pump delivery port zero, the second part of the equation can be disregarded and the pressure ripple written as

$$
\mathrm{P}_{0}=\frac{\mathrm{Q}_{\mathrm{s}} \mathrm{Z}_{\mathrm{s}} \mathrm{Z}_{\mathrm{o}}}{\mathrm{Z}_{\mathrm{s}}+\mathrm{Z}_{\mathrm{o}}}
$$

Defining $\mathrm{Q}_{\mathrm{e}}$ the pressure ripple at entry to delivery line, i. e. the fluidborne noise, and $\mathrm{Q}_{1}$ the pump internal flow losses [3], then

$$
\mathrm{Q}_{\mathrm{s}}=\mathrm{Q}_{\mathrm{e}}+\mathrm{Q}_{1}
$$

being

$$
\mathrm{Q}_{1}=\frac{\mathrm{P}_{0}}{\mathrm{Z}_{\mathrm{s}}}
$$

and, referring to eq. (1),

$$
\mathrm{Q}_{\mathrm{e}}=\frac{\mathrm{P}_{0}}{\mathrm{Z}_{\mathrm{o}}}
$$

Moreover the absence of reflections along the circuit is such as to justify the hypothesis of a line impedance $Z_{0}$ represented by a simple real quantity, not a frequency complex function

$$
Z_{\mathrm{o}}=\frac{\varrho c}{A} \sqrt{1-\frac{j A R}{\omega \varrho}}
$$

being $\mathrm{c}$ the fluid sonic velocity, $\mathrm{Q}$ the fluid density, $A$ and $R$ the line cross-sectional area and its pressure loss, respectively, $\omega$ the pumping frequency.

\section{RELEVANT TEST METHOD}

Referring to the equations above discussed, the source impedance $Z_{s}$ and the pump ideal flow ripple $Q_{S}$ known, in principle it is possible to evaluate the behaviour of the pump flow ripple at entry to delivery line $\mathrm{Q}_{\mathrm{e}}$, i.e. the pump fluidborne noise, and that of the pump internal flow losses $Q_{1}$. Really the test method here presented allows the measurement of all the quantities above making it possible the exhaustive description of pump acoustic and functional characteristics.

A simple and of small size experimental set-up (FIGURE 1) is used. It consists of an hydraulic circuit made by a $1.4 \mathrm{~m}$ delivery line ending with a variable capacity (12 l maximum) with an adjustable diaphragm at its entrance and a downstream load valve.

The test procedure consists in the following steps: - achievement of the best circuit reflectionless conditions adjusting the diaphragm with regard to the loading pressure and comparing the waveforms of the pressure signal at four different points of the delivery line [3];

- more objective evaluation of these conditions by the computation of the termination reflection coefficient. On this purpose we avail ourself of the general wave transmission equation of this circuit and measure transfer functions between two pressure values at any two points of the line $\mid 4]$;

- acquisition of the pressure ripple closest to the 
pump delivery port and computation of the characteristic source impedance $Z_{s}$ and the ideal flow ripple $\mathrm{Q}_{\mathrm{s}}$. Two different diameter pipes acting as independent impedance values at the pump outlet port are used on this purpose, being $\mathrm{Z}_{\mathrm{S}}$ and $\mathrm{Q}_{\mathrm{s}}$ two unknowns of an only equation (eq. (1)). So the pressure ripples $\mathrm{P}_{1}$ and $\mathrm{P}_{2}$ at the pump delivery port measured with pipes of characteristic impedances $\mathrm{Z}_{\mathrm{O} 1}$ and $\mathrm{Z}_{\mathrm{O} 2}$, respectively, allow the computation of $Z_{S}$ and $Q_{s}$ making use of the following two equations:

$$
\mathrm{Z}_{\mathrm{s}}=\mathrm{Z}_{\mathrm{o} 1}\left[\frac{1-\mathrm{H}_{12}}{\mathrm{H}_{12}-\frac{\mathrm{Z}_{\mathrm{o} 1}}{\mathrm{Z}_{\mathrm{o} 2}}}\right]
$$

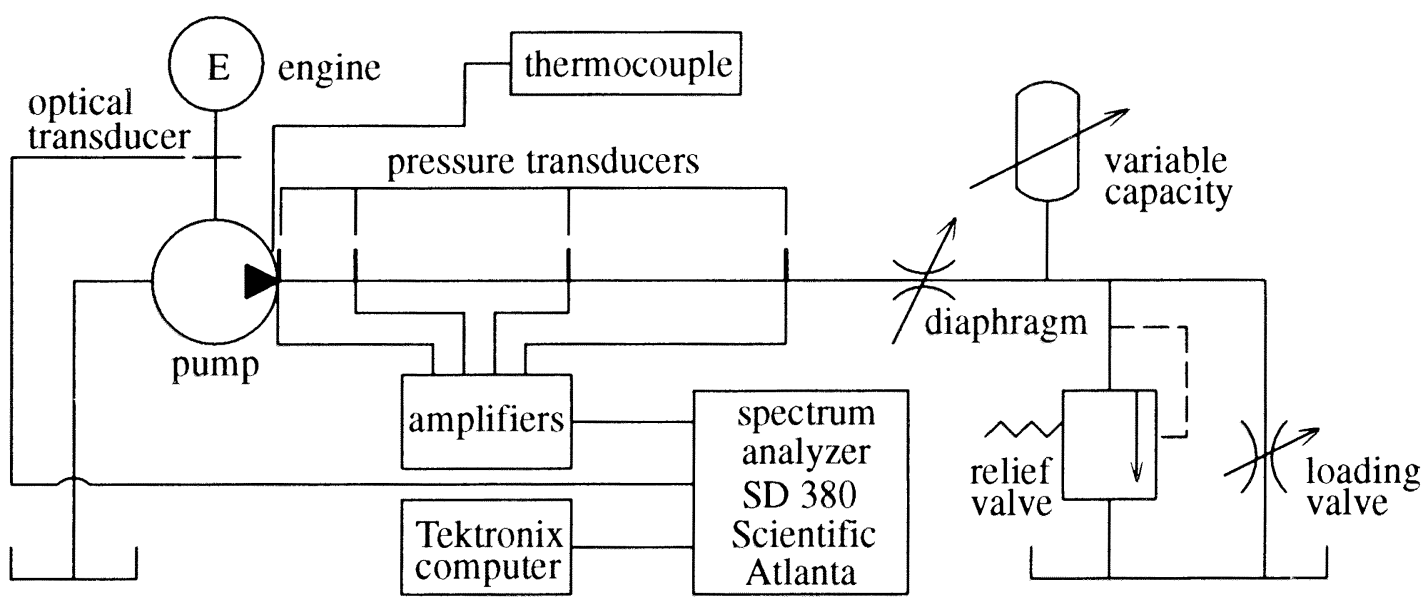

Figure 1 - Test method experimental set-up are used for the pressure ripples harmonic analysis and the complex data reduction in order to obtain the source impedance $Z_{s}$ and the ideal flow ripple $Q_{s}$.

The test procedure described needs an optical transducer for detecting a pulse signal at the same frequency as that of the pressure ripple. This signal is used to provide a synchronisation and the same phase reference for the second data acquisition when the different diameter line is substituted in the circuit.

\section{AXIAL PISTON PUMP APPLICATION}

A variable displacement axial piston pump has been studied by the test method above described in order to characterize its acoustic and functional behaviour.

The pump has been tested at its maximum displacement ( $13 \mathrm{cucm} / \mathrm{rev})$, at loading pressures of 40 bar and 90 bar, $40{ }^{\circ} \mathrm{C}$ to $60^{\circ} \mathrm{C}$ operating temperature

$$
\mathrm{Q}_{\mathrm{s}}=\mathrm{P}_{1}\left(\frac{1}{\mathrm{Z}_{\mathrm{o} 1}}+\frac{1}{\mathrm{Z}_{\mathrm{s}}}\right)=\mathrm{Q}_{\mathrm{e}}+\mathrm{Q}_{1}
$$

being $\mathrm{H}_{12}=\frac{\mathrm{P}_{1}}{\mathrm{P}_{2}}$.

- computation of the internal flow losses $Q_{1}$ and the fluidborne noise $Q_{e}$ from Eq.(3) and Eq.(4).

The three complex quantities $\mathrm{Q}_{\mathrm{s}}, \mathrm{Q}_{\mathrm{e}}$ and $\mathrm{Q}_{\mathrm{l}}$ are represented, magnitude and phase, vs frequency at the pumping fundamental frequency and relevant harmonics or, in a more meaningful way, vs time by the inverse Fourier transform.
A spectrum analyzer and an interfaced computer

range.

Two structural parameters have been mostly considered in order to investigate its noisy behaviour:

- pump swash plate;

- pump port plate.

Principal attention has been paid on the swash plate. Really it has been evaluated one of the major causes of vibration and therefore of noise pointed out mainly by the pump delivery port transducer.

Referring also to preliminary results of a previous research [4], it has been verified that a better swash plate fastener has as consequences:

- a considerable lowering of all three flow ripples $\mathrm{Q}_{\mathrm{s}}, \mathrm{Q}_{\mathrm{e}}$ and $\mathrm{Q}_{\mathrm{l}}$;

- a source impedance $\mathrm{Z}_{\mathrm{s}}$ shifting towards higher frequencies, owing to more compact geometry.

Moreover, in order to better understand the cause of the vibration transmitted by the swash plate ad- 
justing shaft, acoustical and functional performance of the standard pump with a swash plate external fastener as to simulate the normal working conditions has been checked. The pump has then been tested equipped with the same pistons block but with a fixed swash plate casing on purpose built.

FIGURES 2 and 3 compare $Z_{s}$ source impedance behaviours, magnitude and phase, referring to the two pump configurations ((o) fixed swash plate pump). Loading pressure is 90 bar and pump has been tested at fixed speed of $1500 \mathrm{rev} / \mathrm{min}$ so that impedance has been evaluated only at harmonics of pumping frequency $(175 \mathrm{~Hz}$, the pump having 7 pistons).

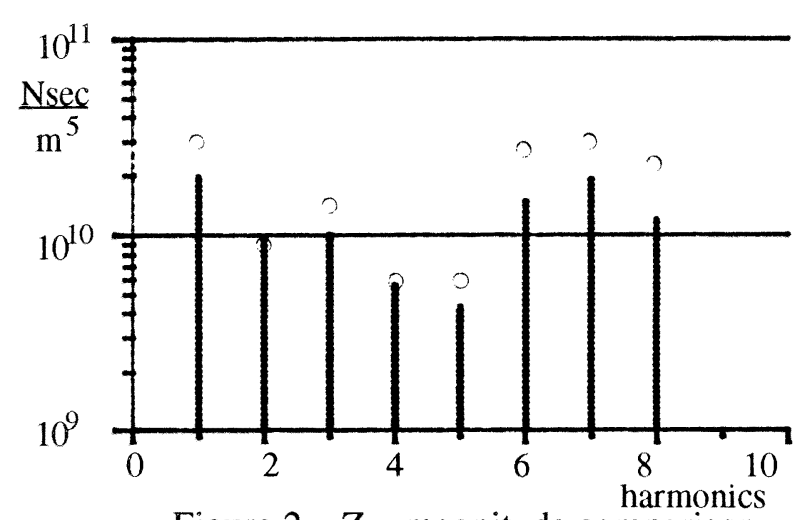

Figure $2-Z_{S}$ magnitude comparison

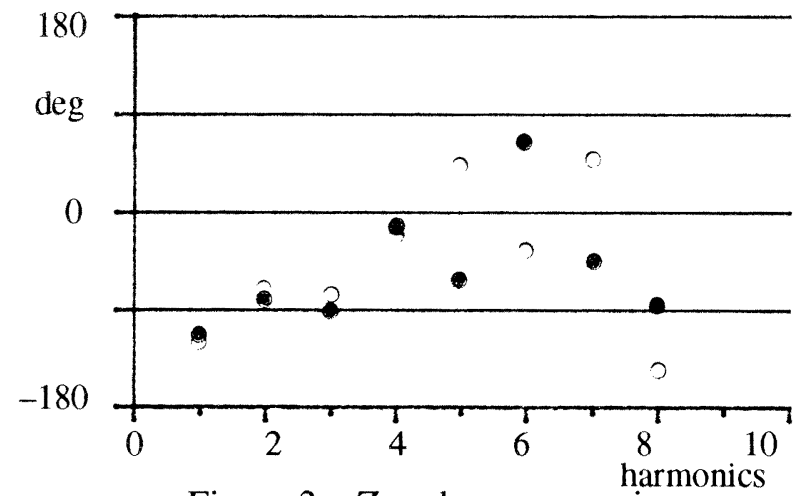

Figure $3-Z_{S}$ phase comparison

FIGURES 4 and 5 show the comparison between the couples of flow ripples $Q_{e}$ and $Q_{l}$ for these two case studies.

The $Z_{s}$ magnitude and phase behaviours emphasize indeed a good experimental data acquisition. The presence of a monotonic decrement between 1 $\mathrm{kHz}$ and $2 \mathrm{kHz}$ with a phase change from -90 deg to positive values agrees with literature and results we obtained for different kinds of pumps [5].

The almost egual trend suggests the absence of important structural differences between the two pump configurations. The value of $Z_{S}$ on the whole a little higher for the fixed swash plate pump (o) is confirmed by its lower leakage flow ripple $\mathrm{Q}_{1}$ (FIGURE
5). That agrees with the source impedance physical meaning, i.e. an evaluation parameter of pump internal flow losses.

The $\mathrm{Q}_{\mathrm{e}}$ fluidborne noise oscillations (FIGURE 4) answer for the influence of the inertia of the fluid entering and coming out the cilinder. On the other hand, the $\mathrm{Q}_{\mathrm{e}}$ trends are quite comparable, as confirmed also by the energy content of their spectral representations. The same results obtained for all the other test conditions, tolerances of the mechanical parts during the work cycle can justify such a kind of differences.

What can be argued from this analysis is that vibrations transmitted to the pump casing by the swash plate, with consequent airborne noise emitted and hydraulic components lifetime reduction, can not be satisfactorily controlled by fastening the relevant adjusting shaft. On this purpose it turns out more useful instead studying the contact mechanism of the pump pistons on the swash plate and the relevant reacting forces.

The influence of the kidney ports shapes of axial piston pump port plate is known from literature and furthermore it has already been verified by means of the same test procedure [4]. Particularly a comparison of pump acoustical and functional performance has been already carried out using three pump port plates with the following different shapes:

- kidney ports without timing notches;

- kidney ports with timing notches;

- shape b) with suction port modification.

This time the effect of a 2 deg rotation of a standard port plate has been investigated. The suction and delivery kidney ports are modelled with timing notches, the best solution achieved in terms of pump acoustical and functional performance.

The rotation has as a consequence the suction and delivery opening in advance. The resulting effect is an improvement of the pump working conditions. Really all three flow ripples $Q_{s}, Q_{e}$ and $Q_{l}$ show more regular trends with reduced oscillations.

As an example, FIGURE 6 reports the $\mathrm{Q}_{s}$ comparison for the fixed swash plate pump at a loading pressure of $40 \mathrm{bar}, \mathrm{Q}_{\mathrm{e}}$ and $\mathrm{Q}_{1}$ comparisons being not less meaningful.

\section{ALTERNATIVE TEST PROCEDURE}

The limits of the test method above described have been evaluated: 

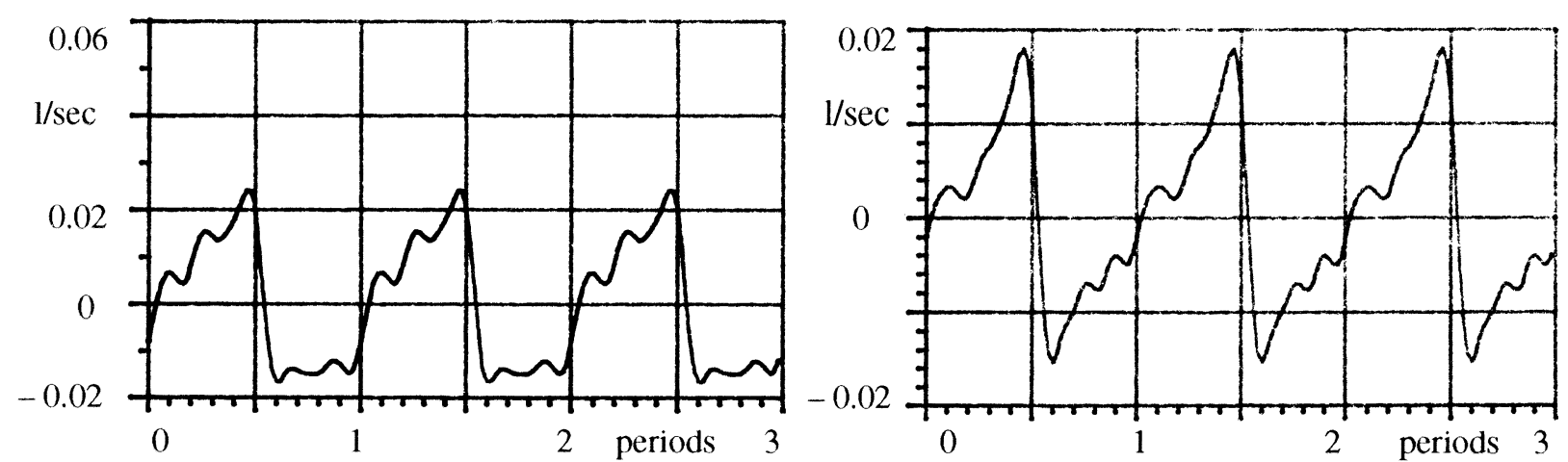

Figure 4 - Flow ripple $Q_{\mathrm{e}}$, variable and fixed swash plate
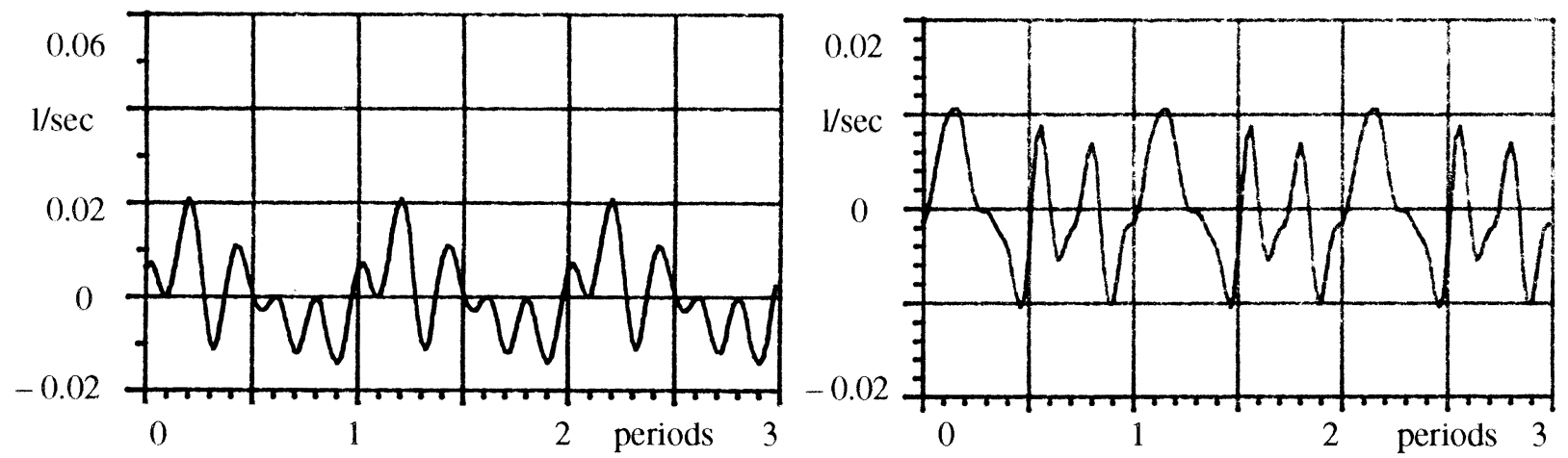

Figure 5 - Flow ripple $Q_{1}$, variable and fixed swash plate
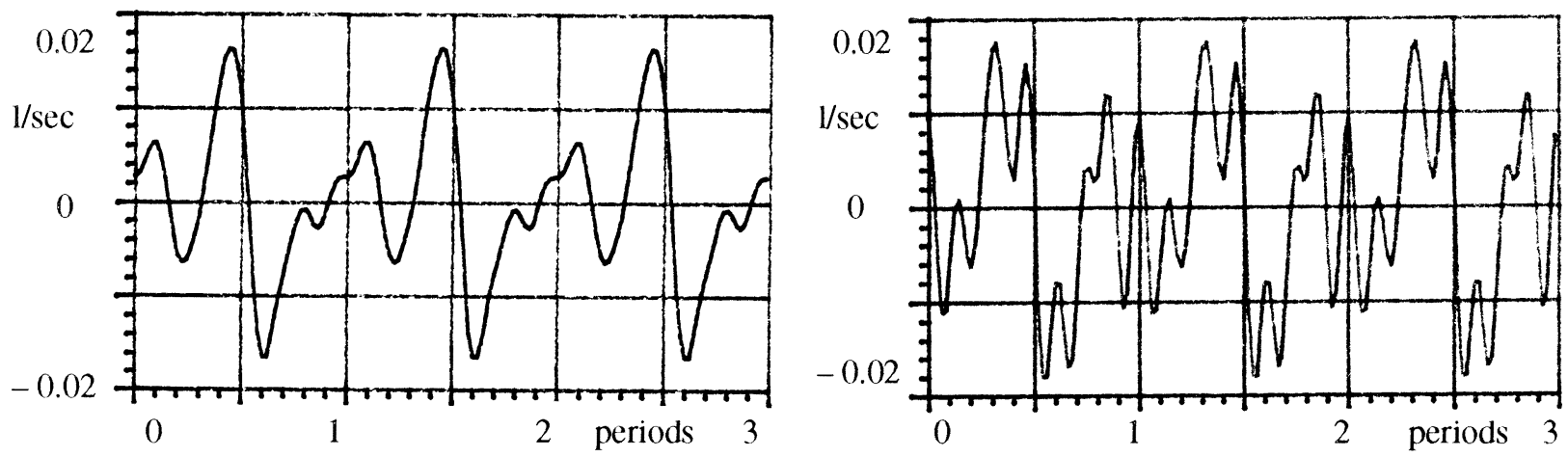

Figure 6 - Flow ripple $Q_{\mathrm{S}}, 2$ deg rotation and standard port plate

- the assumption of really circuit reflectionless conditions;

- the hypothesis of the line impedence $\mathrm{Z}_{\mathrm{O}}$ being a simple real quantity, not a frequency complex function (eq. (5));

- the necessity of using two pipes of different impedances to calculate the values of $Z_{S}$ and $Q_{S}$ with requirement of a same phase reference for the two data acquisitions and change of test experimental set-up conditions.

In order to overcome them, an alternative test method has been optimized. It makes use simply of pressure ripple measurements along only one line with different loading conditions and computer pro-

grams on purpose worked out.

Particularly this method allows the computation of the source impedance $Z_{s}$ and the ideal flow ripple $\mathrm{Q}_{\mathrm{S}}$ from pressure ripple data acquired with different line working conditions. This multi-load test procedure is based on the knowledge of the followig parameters as input to the computer program:

- termination line reflection coefficient;

- sound speed in the fluid for different diaphragm adjustments.

The evaluation of the above parameters is achieved by means of another computer program. This takes the computer-aided stationary transducer fluidborne noise measurement technique [6] as starting 
point and has been specialized for our experimental set-up. The program provides estimates of important fluidborne noise parameters as termination pressure value, position of the actual maximum of the stationary wave, sonic speed and termination reflection factor using the pressure ripple values at four different points of the line. It finds the best fit of a set of equations to the acquired data, varying the four

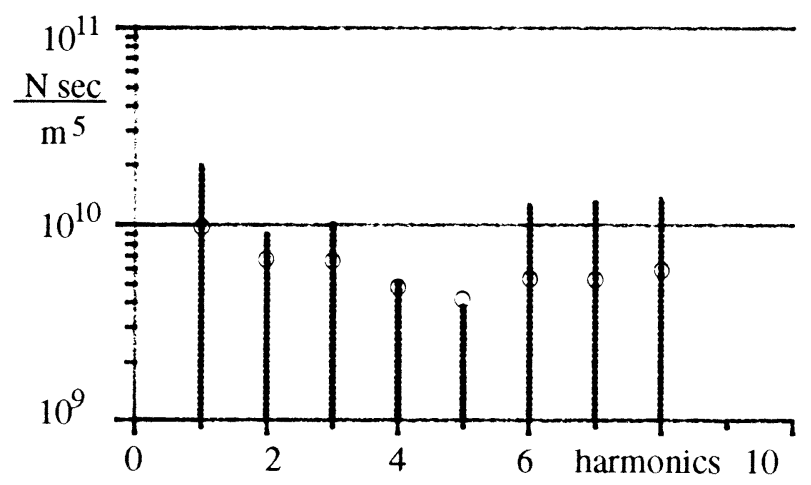

Figure $7-Z_{S}$ magnitude comparison

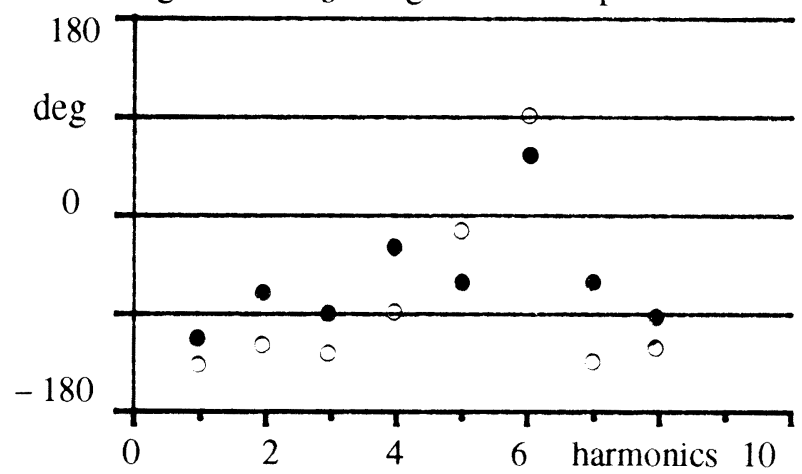

Figure $8-Z_{S}$ phase comparison quantities above.

As an example, FIGURES 7 and 8 report a comparison of $Z_{s}$ values, magnitude and phase, obtained with the two test procedures $((0)$ the alternative one) for the variable swash plate pump at 90 bar loading pressure. Analogous behaviour has been also found for the fixed swash plate and all the other test conditions.

The results of the multi-load test method do not match very well those obtained with the standard test procedure and are less reliable. Notwithstanding that, $Z_{\mathrm{s}}$ antiresonance turns out well located both in terms of magnitude and phase.

\section{CONCLUSIONS}

A test procedure has been applied in order to characterize a variable displacement axial piston pump as to its acoustical and functional performance. Pump swash and port plates have been the structural parameters investigated.

Some limits relevant mainly to the experimental set-up verified, an alternative test method has been proposed.

Results this way obtained do not match wery well those of the standard procedure and show less reliability. Their dependence on difficulty measurable parameters as, for instance, sound speed in the fluid and termination reflection coefficient justify this trend particularly in case of a very noisy pump.

\section{REFERENCES}

1. Viersma, T.J., Analysis. Synthesis and Design of Hydraulic Servosystems and Pipelines. Elsevier, 1980, pp.129-147.

2. Edge, K.A., The theoretical prediction of the impedance of positive displacement pumps. I.Mech.E., C387/80, 1980, pp.95-103.

3. Theissen, H., Die beruecksichtigung instationaerer rohrstroemung bei der simulation hydraulischer anlagen. 1983, Aachen.

4. Miccoli, G., Pump acoustical and functional performance by source impedance evaluation. 10. Aachener Fluidtechnisches Kolloquium, Aachen, Germany, 1992, Vol.II, pp.149-165.

5. Miccoli, G. and Bragion, A., Gear pump fluidborne noise by source flow and impedance evaluation. NoiseCon 88, West Lafayette, Indiana, Usa, 1988, pp.487-492.

6. O'Neal, D.L. and Maroney, G.E., A computer-aided stationary transducer fluidborne noise measurement technique. The BFPR Journal, 1978, 11, 1, 31-40. 